Scientific Bulletin, № 2, 2021, pages 154-164

Fazila Ramiz Nabiyeva, nebiyeva.fazile@mail.ru

National Conservatory of Azerbaijan

DOI: doi.org/10.54414/yhpv3291

e-ISSN: $2789-4614$

\title{
ROUND DANCE IN THE SYSTEM OF INTER-CONFESSIONALRELATIONS IN MODERN AZERBAIJAN
}

\section{ABSTRACT}

In presented article the author sounds idea that optimum attitudes between various faiths in Azerbaijan rely to centuries-old historical traditions. Presents Azerbaijan territory as the centre of merge of diverse cultures and directs to it reader's attention as country, where separate religions Islam, Christianity, Judaism function.

The reader's attention is drawn to examples of the circular dances of some small peoples. The author considers the circular dances found in the cultures of individual Nations as the unity of the multicultural world. The article also refers to the role of such dances in the system of various interfaith relations.

Keywords: Azerbaijan, nation, population, ethnoconfessional, religion, culture, round dance

\section{MÜASIR AZORBAYCANDA \\ KONFESSIY ALARARASI ӘLAQӘ \\ SISTEMINDӘ DAİRəVİ RəQSLӘR}

\section{XÜLASכ}

Təqdim edilən məqalədə müəllif Azərbaycanda müxtəlif konfessiyalar arasında olan optimal münasibətlərin çoxəsrlik tarixi ənənələrə söykəndiyi fikrini qeyd edir. Azərbaycan ərazisini müxtəlif mədəniyyətlərin qovuşduğu mərkəz kimi təqdim edir və ayrı-ayrı dinlərin - islamın, xristianlığın, iudaizmin fəaliyyət göstərdiyi bir ölkə kimi oxucunun nəzərinə çatdırır.

Oxucunun diqqəti bəzi azsaylı xalqların dairəvi rəqs nümunələrinə yönəldilir. Müəllif ayrı-ayrı xalqların mədəniyyətində rast gəlinən dairəvi rəqsləri multikultural dünyanın vəhdəti kimi qiymətləndirir. Məqalədə həmçinin, belə rəqslərin müxtəlif konfessiyalararası əlaqə sistemindəki rolundan bəhs edilir.

Açar sözlər: Azərbaycan, əhali, xalq, etnokonfessional, din, mədəniyyət, dairəvi rəqslər

\section{КРУГОВЫЕ ТАНЦЫ В СИСТЕМЕ МЕЖКОНФЕССИОНАЛЬНЫХ СВЯЗЕЙ В СОВРЕМЕННОМАЗЕРБАЙДЖАНЕ}

\section{РЕЗЮМЕ}

В представленной статье автор озвучивает мысль о том, что оптимальные отношения между различными конфессиями в Азербайджане опираются на многовековые исторические традиции, представляя территорию Азербайджана как центр слияния разнообразных культур и направляя к нему внимание читателя в качестве страны, где функционируют отдельные религии - ислам, христианство, иудаизм. Внимание читателя обращается к образцам круговых танцев некоторых малочисленных народов. Автор расценивает круговые танцы, встречаемые в культурах отдельных народов, как единство мультикультурного мира. В статье также говорится о роли таких танцев в системе различных межконфесиональных связей.

Ключевые слова: Азербайджан, народ, население, этноконфессия, религия, культура, круговые танцы 
«Многонациональность, толерантность Азербайджана это наше богатство и преимущество»

Общенациональный лидер Гейдар Алиев

Многонациональный Азербайджан для разных народов является родным местом проживания в атмосфере взаимопонимания. Гуманизм азербайджанского народа, не допускающий национальной и религиозной дискриминации, создал благоприятные условия для проживания в стране малочисленных народов и этнических групп. Наша толерантная страна, где, наряду с азербайджанскими тюрками, проживают представители тюркской ветви алтайской языковой семьи, а также индоевропейской, кавказской и славянской языковых групп, является местом проживания представителей более 100 этносов. Среди них можно выделить горских евреев, татов, талышей, курдов, ингилоев, аваров, лезгинов, хыналыгцев, удинов и др. Каждый из этих этносов, будучи носителем духовных ценностей, общих с азербайджанскими тюрками, вместе с тем сохраняют по сей день ряд своих этнических особенностей, тем самым придавая мультикультурализму Азербайджана своеобразные оттенки.

В Азербайджане, который является мостом между двумя различными цивилизациями, оптимальные отношения между государством и религией, между различными конфессиями, основываются на многовековые исторические традиции. Азербайджанские тюрки и Азербайджан ское государство не осуществляют по национальной и религиозной дискриминации в отношении представителей народов, проживающих на территории нашей республики. 96\% населения страны это мусульмане, $4 \%$ - представители других религий, в том числе протестанты, православные, представители албано-удинской церкви, иудеи, бахаи, молокане, кришнаиты и др. [3, с.362]. На территории Азербайджана действует 1802 мечетей, 5 православных, 1 католическая, 4 Грузинских православных церквей, 6 синагог и другие места поклонения.

Как известно, мультикультурализм проявляется в разных жанрах искусства, в том числе и в танцевальном искусстве. Круговые танцы, ко торые встречаются в культуре разных народов, можно признать, как проявление в мире единства мультикультурализма. Присутствие круговых танцев в культуре малочисленных народов, проживающих на территории Азербайджана наряду с его древними жителями и являющихся носителя ми других языков и представителями иных религией, есть проявление общности и единства между ними. Круговые танцы малочисленных народов Азербайджана, обогащающие азербайджанский мультикультурализм и выделяющиеся своей спецификой, можно сравнить с отдельными петлями ковра.

Следует отметить, что в современных круговых танцах проявляется 
поклонение людей раннего периода истории «Небесному Божеству». В Азербайджане существуют места проживания в форме круга, символизирующего культ солнца, что указывает на древнее происхождение этих мест и зарождение ранней культуры. По мнению Н.Рзаева, в представлениях наших предков солнце воспринималось как Бог Огня, Бог Пламени, Дух Ал же - как дух солнца [4, с. 25]. Ученый считает, что поклонение солнцу занимало видное место в идеологии всей эпохи бронзы. Культ Солнца нашел свое отражение и в культурных памятниках бронзовой эпохи. По мнению ученого, «кромлехи» (слово «Kromlex» происходит от французских слов «krom»- круг и «lex»- камень: Н.Ф.), построенные в форме концентрированного круга, являются храмами Солнца. Н.Рзаев также отмечает, что в этих храмах исполняли ритуалы, посвященные солнцу. Таким образом, круглая форма храмов связана с культом Солнца. В Гобустане и Ханкенди встречаются кромлехи в форме обычного круга, а в Апшеронском районе, в местечке «Аг даш» («Белый камень»), расположенном на окраине села Шувелан - кромлехи в форме концентрического круга $[5$, с.53]. Отметим также то, что круглые курганы как в Азербайджане, так и в отдельных уголках мира.

А теперь, в соответствии с темой и с учетом объема представленных статей, постараемся описать круговые танцы как азербайджанских тюрков, так и некоторых малочисленных народов, проживающих на территории нашей страны.

Танец «Яллы» (хоровод), массово исполняемый азербайджанцами, входящими в Огузскую группу тюркских языков и исповедующими ислам, отражает в себе сплоченность и единство. На территории Нахичеванской АР зафиксировано около 100 разновидностей этого танца. Также известно исполнение танца «Яллы» в Масаллах, Ленкорани, Шеки и Газахе. Во время исполнения танца во главе группы, состоящей из мужчин и женщин, стоит с платком или палкой в руках «ялльбашы», который ведет за собой других участников танца. Участника танца, замыкающего круг, называют «аягчыl». «Яллы» начинается в тяжелом темпе, постепенно убыстряясь.

Существуют различные мнения об этимологии слова «Яллы». По мнению И.Багирова, слово «яллы» произошло от слова «ян» (гореть, огонь, пламя). В эпоху открытия и освоения огня возникла необходимость сохранить огонь, уберечь его, установив вокруг него ограждение. В древности с целью охраны огня вокруг костра выстраивались хранители огня. Постепенно это доходило до той стадии, что приобретало форму организованной игры» [2, с.13]. В книге Э.Асланова «Игры, зрелища, народные представления» отмечается, что слово «яллы» происходит от слова «яйлы», а также то, что танец имеет древние корни и является ритуальной игрой, исполняемой с целью охоты и сбережения 
огня. В некоторых местностях эту игру называют «эл-эле» (рука об руку), «лялли» или «ялли» [1, с. 94]. На наш взгляд, целесообразно рассмотрение комментариев ученого-лингвиста М.Сеидова, связанных с этимологическим анализом слова «яллы». По мнению ученого, название танца «яллы» образовано от слов «ял+од» и тесно связано с «высоким именем», т.е. с солнцем. Тогда «Яллы» означает «ял+лы», «алов+лу», «од+лу», «гюнеш+ли», то есть огненный, солнечный, пламенный. Вероятно, что древние азербайджанцы в обряде в честь огня, пламени исполняли первичный вариант этого танца. Возможно этот танец сопровождался песней, а в первичном варианте и восклицаниями» [6, с. 79-80]. На наш взгляд, комментарии М.Сеидова касательно этимологического анализа слова «яллы», полностью раскрывают сущность этого слова.

По нашему мнению, связь корня этого слова с различными словами азербайджанского языка подтверждает то, что в ходе процессов истори ческого развития «Яллы» постепенно перешел из обряда в массовый народный танец.

«Шареи», «Гопу», «Урфани», «Телло», «Кюрдюн агыры», «Фести валы», «Хяляфи», «Галадан-галая» [9] и другие входят в ряд древнеазербайджанских танцев «яллы».

Нотный пример № 1

ХЯЛЯФИ
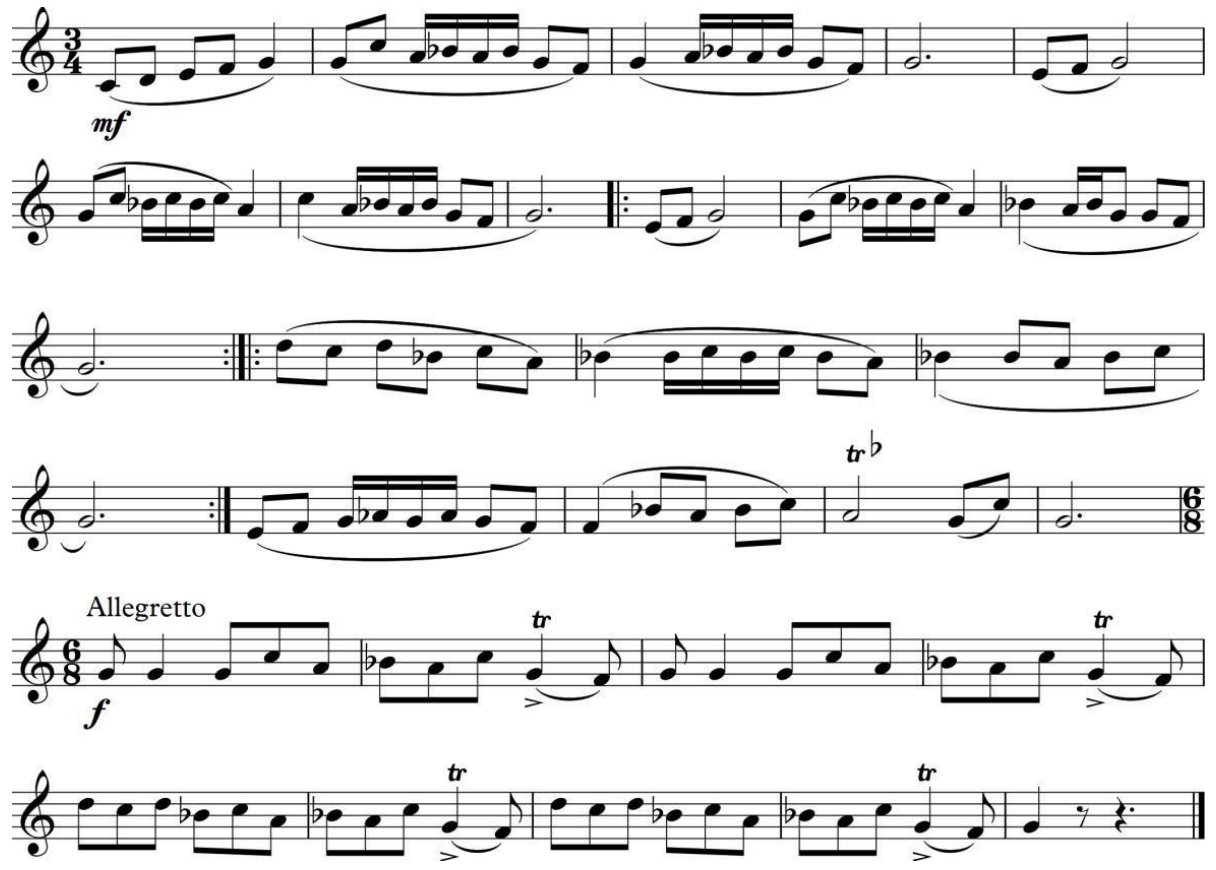

В национальном составе и удельном весе населения Азербайджана второе место занимают русские, которые относятся к восточнославянс- 
кой группе индоевропейской языковой семьи. Их приход в Азербайджан приходится в основном на 30-40-е годы 19 века. В настоящее время большинство русских живут в городах Азербайджана и преимущественно в Баку [8]. Большая часть русских - православные христиане.

В русских народных танцах, имеющих древние корни, широко распространены игры и хороводы. В хороводах, которые относятся к синкретическому виду народного творчества и исполняются коллективным выстраиванием в круг, отражаются некоторые древние символы такие, как круговое движение солнца и открытие дверей. В таких танцах ведущий выполняет важную функцию. Русские хороводные танцы по своим особенностям делятся на 4 группы, а по жанру - на 3 вида.

Среди русских хороводных танцев можно выделить такие, как «Вейся, вейся капуста» [10], «Из-под дуба, из-под вяза», «Ты заря, ты моя зоренька», «Тимоня», «Чижик», «Метелица», «Игумен», «Из-за лесику, лесу темного».

Нотный пример № 2

ПЕРАПЁЛАЧКА

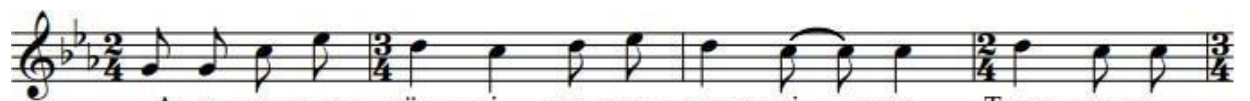

А у пе - ра - пёл - кі ды ста - рэнь - кі муж. Тыж ма-я,

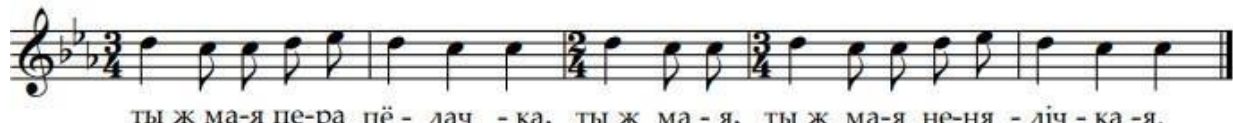

Татары, которые относятся к кыпчакской группе тюркских языков, преимущественно живут в больших городах Азербайджана. Согласно данным, приведенным в источниках, после азербайджанских тюрков и русских, татары образуют третью большую этническую группу жителей Баку. Татары, будучи в большинстве своем мусульманами, являются приверженцами ханафитского мазхаба в рамках ислама сунитского толка [7].

Татарами исполняются такие круговые танцы, как «Айлен-Бейлен уэн» («Тимпаира-Тиратур»), «Тугарак уэн» («Круговая игра»), «Ша», «Лысва сыу буйлары» («На берегу реки Лысва»), «Йылдызым» («Звезда»), «Чылбыр» («Цепь»).

Нотный пример № 3

ТУНЕРЕК УЮНУ
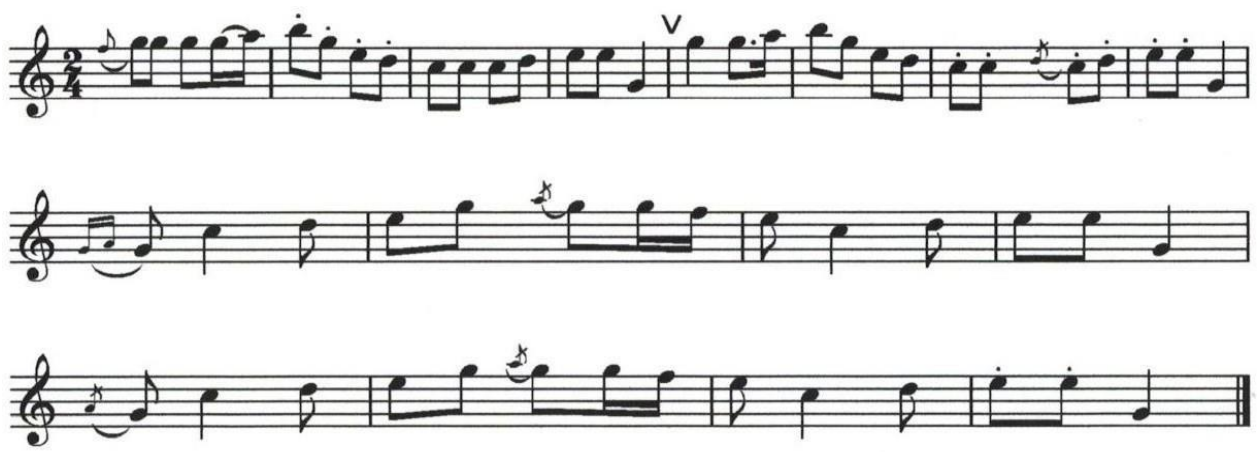
Украинцы относятся к восточнославянской группе индоевропейской языковой семьи. Их переселение в Азербайджан приходится на конец 19 века. С тех времен они обосновались на Апшеронском полуострове и в Хачмазском районе. Азербайджанские украинцы, будучи христианами, исповедуют протестантизм.

В хореографии украинцев хоровод является основным жанром. У украинцев хороводы, появившиеся еще в древние времена, носят такие названия, как «Веснушка», «Гаивка», «Гагилка», в Сумской, Черниговской областях же - «Карагод». Украинские круговые танцы делятся на хороводные игры и хороводные танцы с пением. Хороводными играми украинцев является «Весна-красна», «Ох, Иванчику, бедоланчику», «Метелица» [11].

\section{Нотный пример № 4}

МЕТЕЛИЦА
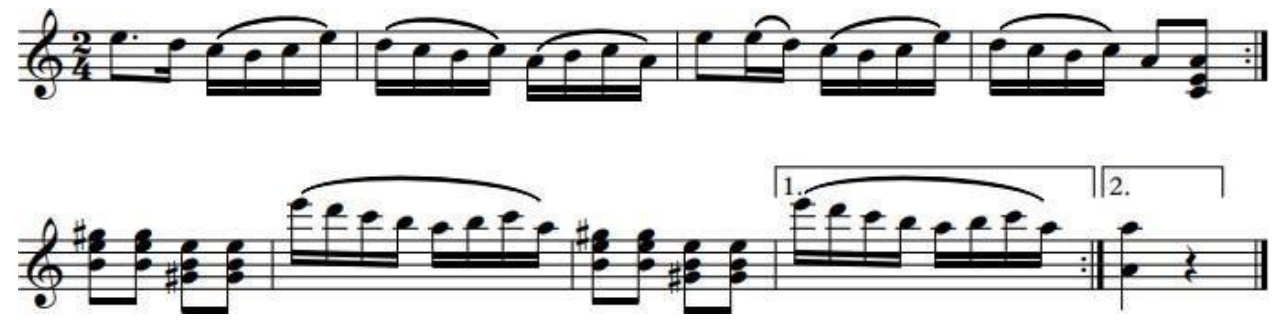

Евреи, которые относятся к евразийской (семитской) языковой группе, прибывали в Азербайджан как до, так и после Рождества Христова, а их переселение в Азербайджан с территории Ирана приходится на 16-й век. Их единственными наследниками (потомками) в Азербайджане являются горские евреи, компактно обосновавшиеся в Губинском районе в селе Красная Слобода, а также в Огузском районе и в Баку. В свое время покинувшие свою историческую Родину и перелившиеся в Иран горские евреи освоили здесь язык татов, продолжая придерживаться основных принципов иудаизма. В Северный Азербайджан они пересели лись в эпоху Сасанидов. В отличие от европейских евреев, поселивших ся в Азербайджане еще с начала 19-го века, на религиозные взгляды горских евреев влияние оказало идолопоклонство, а затем и ислам [8].

«Хора» - это танец, символизирующий их национальную мощь. Во всем мире на протяжении многих лет целью исполнения этого знаменитого танца на праздничных мероприятиях и свадебных церемониях было взявшись за руки сплочение и объединение людей. «Хора» немного отличается от круговых танцев, исполняемых в некоторых странах Восточ ной Европы. «Еврейская Хора» с размером 3/4 или 3/8 в основном исполняется под израильские народные песни и иногда еврейские песни типа «Хава Нагила». Сегодня «Хора» является неотъемлемым атрибутом еврейских свадеб. 
Также к круговым еврейским танцам относятся «Хине ма тов» [12], «Хора Медура», «Эрев Ба», «Земер Атик» и др.

\section{Нотный пример № 5 ЕРЕВ БА}

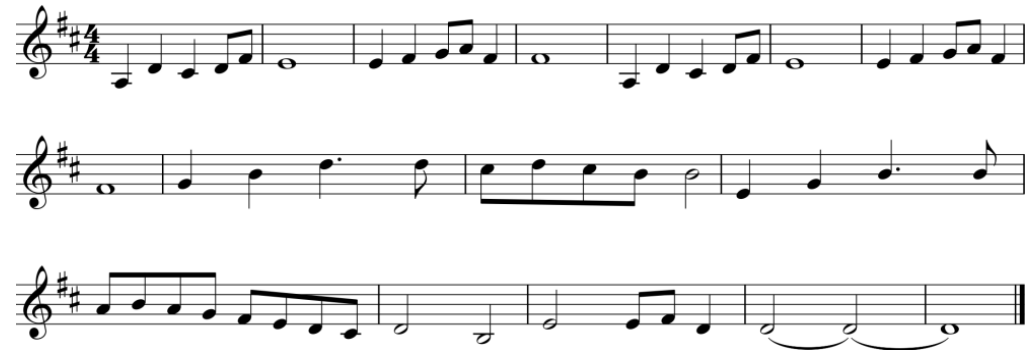

Одним из малочисленных мусульманских народов, проживающих в нашей стране, являются также курды. Курды - мусульмане делятся на суннитов и шиитов. Они относятся к северо-западной полугруппе иранской языковой группы. В настоящее время курды проживают в Нахичеванской АР, в частности в Седерекском районе, в селе Тейваз Джульфинского района и в селе Дерекенд Шарурского района. До вооруженно го конфликта с Арменией курды жили в Лачинском, Кельбаджарском, Губадлинском и Зангеланском районах. В результате оккупации армянами этих территорий курды были вынужденно переселены в другие районы республики.

Курдские танцы - это традиционные групповые танцы, исполняемые участниками танца, взявшись за руки. Курды исполняют круговые танцы на днях рождения, на праздник Новый Год - праздник «Новруз», свадьбах и других мероприятиях. В курдских танцах предводителя танца называют «серщопи». Он в правой руке держит цветной или символичный платок. Других участников танца называют «гаванами». Иногда в круговом танце курдов замыкающего круг танцора тоже называют гаваном. Для исполнения танца возрастных ограничений нет. Можно стать свидетелем участия в танце людей разных возрастов, начиная с 3 -х до 83х лет.

Курдские танцы имеют следующие много различных вариантов: «Горани курди», «Герьян», «Шапи», «Сепе», «Дилан». Танец «Герьян» исполняется в быстром темпе. Танец «Шапи» означает левый и происходит от слов «шеп» или «шап». Это один из простых курдских танцев. «Шапи» исполняется следующим образом: вдоль круга левой ногой два шага вперед и затем правой ногой два шага назад. Танец «Сепе» хореографически схож с танцем «Шапи».

В танце «Говенд у дилан» участники образуют круговую дорожку. Они, держась за руки, выстраиваются в форм полукруга. В руках танцующие держат красочные платки, называемые «десроке». Участники тан- 
ца вместе с предводителем танца, двигаясь по кругу, машут платками. Ведущий часто повторяет движения, характерные для этого танца, или же делает движения по своему желанию. Танец сопровождается инструментальным исполнением и пением певца [13].

Таким образом, в представленной статье мы попытались показать общие черты круговых танцев некоторых малочисленных народов, проживающих в Азербайджане и относящихся к разным языковым группам, а также их межконфессийную роль. На примере таких танцев мы хотели показать, что культура является одним из важных средств регулирования различных межрелигиозных отношений.

Как видно, Азербайджан наряду с тем, что исторически является центром слияния многочисленных культур, так же является средой для межрелигиозных диалогов, толерантности, гармонии и взаимообогащения. Именно поэтому представители различных народов, проживающих в нашей стране, живут в атмосфере дружбы и братства, свободно исповедуют свою религию и исполняют обряды. Все вышесказанное можно расценивать как наглядный пример того, что наша страна с особой чувствительностью относится к взаимоуважению и доверию между представителями отдельных религий.

Отношения государства и религии, основанные на устойчивой концепции и историческом фундаменте, мультикультуралистические взгляды и образ жизни в Азербайджане могу стать примером не только для народов, проживающих на территории нашей страны, но и для демократических государств.

\section{Литература:}

1. Aslanov E.M. El-oba oyunu xalq tamaşası. B..: İşıq, 1984, s. 275

2. Bağırov $\dot{I}$. "Yallı" haqqında bəzi qeydlər. // "Odəbiyyat və incəsənət" qəzeti, 1972, iyul.

3. Niftiyev N.M. Azərbaycanda birgəyaşayış və multikulturalizm. B.: BBMM, 2015. s. 407

4. Rzayev N.I. Osrlərin səsi. B.: ADN, 1974. s. 79

5. Rzayev N.I. Ocdadların izi ilə. B.: Azərbaycan Dövlət NəşriyyatPoliqrafiya Birliyi, 1992, s. 70

6. Seyidli M.M. Azərbaycan xalqının soykökünü düşünərkən. B.: Yazıçı, 1989. s.485

7. Azərbaycanda tatarlar. 13.11.2018. URL: https://az.wikipedia.org/wiki/Az\%C9\%99rbaycanda tatarlar (дата обращения: 18.04.2021)

8. Etnik rəngarənglik. Azərbaycan multukulturalizmi. URL: http://multiculturalism.preslib.az/az_a3.html (дата обращения: 
18.04.2021)

9. Qaladan qalaya yallısı. 19.05.2020. URL:

https://www.youtube.com/watch?v=vij79qlQRuY (дата обращения:

19.04.2021)

10. Хоровод "Вейся, вейся капустка". 14.08.2014. URL:

https://www.youtube.com/watch?v=a2PRmkaK3VA (дата обращения: 18.04.2021)

11. Український народний танець Метелиця. 02.12.2012. URL:

https://www.youtube.com/watch?v=biNR-IZOTK8 (дата обращения: 18.04.2021)

12. Hine Matov (Danza Hebrea) - Mirad Cuan Bueno. 19.03.2014. URL: https://www.youtube.com/watch?v=66Rb4v8e1cQ (дата обращения: 18.04.2021)

13. Govend u Dilan. 29.10.2020. URL:

https://www.youtube.com/watch?v=1z5ATb5mQCY (дата обращения: 19.04.2021) 